\title{
Analysis Of Block Stability For Room And Pillar Coal Mining In Pillar Panel Using Numerical Methods
}

\author{
$1^{\text {st }}$ Novandri Kusuma Wardana ${ }^{1}, 2^{\text {nd }}$ R. Andy Erwin Wijaya ${ }^{2}$ \\ \{novandri.kusuma@itny.ac.id\} \\ Mining Engineering Departement, Institut Teknologi Nasional Yogyakarta ${ }^{1,2}$
}

\begin{abstract}
It is impossible for this industry, which makes a major contribution to the mining sector, to continue to exist unless new technology is developed to make mining economically feasible. This article describes the findings of a study conducted for a complete mining system in PT. X. Main objective of this study was to determine the optimal Pillar and Roof parameters for new mining technique with continuous miner, which was accomplished via simulation. The characteristics of the room and pillar mining systems were determined using the calculation formula and conditional thickness techniques, which ensured that the system would be stable over the long run. The techniques of computation that were employed produced outstanding results.
\end{abstract}

The most significant of these techniques is the increase in coal output via continuous mining, although it is essential to keep an eye on the stability. The influence of the random variation of the actual room sizes on the stability of the immediate and main roofs is minimal and is not taken into account in the calculations of immediate and major roof stability. The results of the investigation revealed that the safety factor for the estimated room size of 8 and $10 \mathrm{~m}$ is insufficient. According to the geological circumstances, the values of dependency immediate roof critical with (IRCW) and pillar management are used in conjunction with each other.

To create a two-dimensional (2D) model of the pillar panel with support design utilizing roof bolt technology, a great deal of work must be done. Therefore, the simulation is carried out at the eaves edge, where the greatest likelihood of roof collapse has been seen. To put it another way, it may be said that simulation is carried out before to the major collapse. An elasto - plastic model has been chosen for investigation, with input parameters including physico-mechanical characteristics, geo-mining conditions, roof bolt and grout qualities, and other variables. The instance of a depillaring panel in an underground coal mine has been selected for investigation. During mine operation, the axial force applied on the bolt is observed to produce the reported outcome. The data from instrumented rock bolts has been collected for the purpose of validating the model based on field observations. The highest axial load generated on the bolt in the model was found to be extremely similar to the maximum axial force measured on the bolt in the field.

Keywords: Stability, pillar, IRCW, pillar management, elasto - plastic model, instrumented roof bolt, 2 dimensional numerical model.

\section{Introduction}


The underground coal mine is now the most popular kind of mining in Indonesia, according to the country's mining industry. In the current practice of support design, two main factors are taken into consideration: the Rock Mass Rating (RMR) and the gallery size. This technique has been developed for the traditional mining approach. RMR has made a number of recommendations for underground tunneling support, most of which are based on empirical dimensioning, such as those made by Terzaghi, Bienawski, and Nick Barton, among others.

The empirical design was created in the coal mining sector, namely during the depillaring process. A generalized empirical equation and mathematical modeling are used in this design methodology to estimate the required support load density at different places on the face based on geotechnical parameters of the mine and physico-mechanical properties of the immediate roof rocks during mechanized coal pillar mining. The calculation is dependent on a number of variables, including the RMR, depth, gallery width, and stress ratio. The elastic model has been utilized to determine the height of the rock load using a numerical simulation method, which has proven successful. In addition to computing the lowest and maximum main stress (,-1. and,3.) in the vicinity of an excavation, the rock load height may be calculated by calculating the safety factor at various points and sketching its contour. In this study, a factor of safety is defined as 1.3 or more.

It is possible to utilize two different kinds of support systems in underground coal mines, which are the Room and Pillar Methods. There are two types of mining: active and passive. The category of supporting systems is divided into three types: rock bolting, wiremesh, and beam. The strength of the rock is increased by internal reinforcing stresses, which are used in the design of the supporting system.

Rock bolting, also known as rock bolting, is a more cost-effective support system for underground mines than other types of support systems since its installation is more simpler than the alternatives. Consequently, it reduces material and labor consumption, allowing the mine's production to increase. It also helps to minimize the failure of rock and the interlocking of rock in subterranean excavations.

Many studies have been conducted in the field of support design, using both the mathematical and empirical approaches, as well as the numerical method. The two-dimensional numerical simulation provides a fair grasp of the complicated roof strata and bolting interaction, which allows for more accurate analysis (convergence confinement). According to the computational model, the roof bolts may have a considerable impact on the vertical stress distribution in the bolted region. As a result, the creation of a 2D roof bolt model will be very beneficial to future study into bolt/rock interaction.

In this study, an effort has been made to evaluate the roof bolting system while it is operating under the influence of pillars using the numerical simulation technique. The behavior of the axial stress on the roof has been studied and understood.

\section{Theory}

\subsection{Finite element methods}

Two-dimensional finite element analysis was used to simulate the numerical modeling, which was done using the software RS2 created by Rocscience 2019 Incorporated. To simulate threedimensional advancement of the goaf edge, a multistage two-dimensional plane strain model was developed. This was accomplished using the core replacement technique, which simulates progressive modeling by incrementally replacing the core with a new material possessing identical or reduced stiffness without any initial element loading. 
A matrix equation is created by connecting the input at certain places in the elements (the nodes) to the output at the corresponding points in the elements. Alternatively, "element-by-element" methods may be used to prevent the creation of (big) global matrices while attempting to solve equations across vast areas by summing the matrix equations for smaller sub-regions node by node, resulting in global matrix equations. Even though the method has already been described in a number of texts, including Zienkiewicz and Taylor (1989), Strang and Fix (1973), Cook et al. (1989), and Rao (1989), the principles of the method will be briefly described in this chapter to establish a notation and to set the stage for the subsequent descriptions of programming techniques in the following chapters.

If the wall may be assumed to be of unit thickness and to be in a condition of planar stress (as suggested by Timoshenko and Goodier, 1982), the equations that must be solved are as follows:

1. Equilibrium

$\frac{\partial \sigma_{x}}{\partial x}+\frac{\partial \tau_{x y}}{\partial y}+F_{x}=0$
$\frac{\partial \tau_{x y}}{\partial x}+\frac{\partial \sigma_{x}}{\partial y}+F_{y}=0$

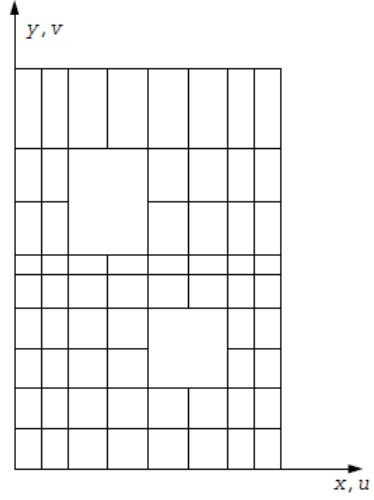

(a)

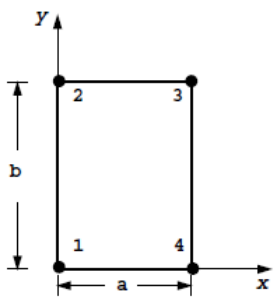

(b)

Where of the component $\sigma_{x}, \sigma_{y}$, dan $\tau_{x y}$ are the only non-zero component stress non zero and $F_{x}, F_{y}$ are body forces (unit of force/length ${ }^{3}$ ).

2. Constitutive (plane stress)

$$
\left\{\begin{array}{c}
\sigma_{x} \\
\sigma_{y} \\
\tau_{x y}
\end{array}\right\}=\frac{E}{1-v^{2}}\left[\begin{array}{ccc}
1 & v & 0 \\
v & 1 & 0 \\
0 & 0 & \frac{1-v}{2}
\end{array}\right]\left\{\begin{array}{c}
\epsilon_{x} \\
\epsilon_{y} \\
\gamma_{x y}
\end{array}\right\}
$$

where E is Young's Modulus, $v$ Poisson's ratio and $\epsilon_{x}, \epsilon_{y}$ and $\gamma_{x y}$ are the independent small strain components.

3. Strain-displacement 


$$
\left\{\begin{array}{c}
\epsilon_{x} \\
\epsilon_{y} \\
\gamma_{x y}
\end{array}\right\}=\left[\begin{array}{cc}
\frac{\partial}{\partial x} & 0 \\
0 & \frac{\partial}{\partial y} \\
\frac{\partial}{\partial y} & \frac{\partial}{\partial x}
\end{array}\right]\left\{\begin{array}{l}
u \\
v
\end{array}\right\}
$$

where $u$ and $v$ are the components of displacement in the $x$ dan $y$ directions. Equations 2 and 3 can be written in :

$$
\begin{aligned}
& {[\boldsymbol{A}]^{T}\{\boldsymbol{\sigma}\}=-\{\boldsymbol{f}\}} \\
& \{\boldsymbol{\sigma}\}=[\boldsymbol{D}]\{\boldsymbol{\epsilon}\} \\
& \{\boldsymbol{\epsilon}\}=[\boldsymbol{A}]\{\boldsymbol{e}\} \ldots \ldots
\end{aligned}
$$

Where ;

$\{\boldsymbol{\sigma}\}=\left\{\begin{array}{c}\sigma_{x} \\ \sigma_{y} \\ \tau_{x y}\end{array}\right\},\{\boldsymbol{\epsilon}\}=\left\{\begin{array}{c}\epsilon_{x} \\ \epsilon_{y} \\ \gamma_{x y}\end{array}\right\},\{\boldsymbol{e}\}=\left\{\begin{array}{l}u \\ v\end{array}\right\},\{\boldsymbol{f}\}=\left\{\begin{array}{l}F_{x} \\ F_{y}\end{array}\right\}$

$[\boldsymbol{A}]=\left[\begin{array}{cc}\frac{\partial}{\partial x} & 0 \\ 0 & \frac{\partial}{\partial y} \\ \frac{\partial}{\partial y} & \frac{\partial}{\partial x}\end{array}\right], \quad[\boldsymbol{D}]=\frac{E}{1-v^{2}}\left[\begin{array}{ccc}1 & v & 0 \\ v & 1 & 0 \\ 0 & 0 & \frac{1-v}{2}\end{array}\right] \ldots$

We shall only be concerned in this book with "displacement" formulations in which $\{\boldsymbol{\sigma}\}$ and $\{\boldsymbol{\epsilon}\}$ are eliminated from 3.15 as follows :

$[\boldsymbol{A}]^{T}\{\boldsymbol{\sigma}\}=-\{\boldsymbol{f}\}$

$[A]^{T}[D]\{\in\}=-\{\boldsymbol{f}\}$

$[\boldsymbol{A}]^{T}[\boldsymbol{D}][\boldsymbol{A}]\{\boldsymbol{e}\}=-\{\boldsymbol{f}\} \ldots$

Writing out $(1-7)$ in full we have :

$\frac{E}{1-v^{2}}\left\{\begin{array}{l}\frac{\partial^{2} u}{\partial x^{2}}+\frac{1-v}{2} \frac{\partial^{2} u}{\partial y^{2}}+v \frac{\partial^{2} v}{\partial x \partial y}+\frac{1-v}{2} \frac{\partial^{2} v}{\partial y \partial x} \\ v \frac{\partial^{2} u}{\partial y \partial x}+\frac{1-v}{2} \frac{\partial^{2} u}{\partial x \partial y}+\frac{1-v}{2} \frac{\partial^{2} v}{\partial x^{2}}+\frac{\partial^{2} v}{\partial y^{2}}\end{array}\right\}=\left\{\begin{array}{l}-F_{x} \\ -F_{y}\end{array}\right\}$

\subsection{Pillar Load}

The load in the pillar can be expressed by in closed form below :

$\frac{P}{W_{p}^{2}}=\frac{\left(W_{o}+W_{p}\right)^{2} \gamma h}{W_{p}^{2}}$ 
$\sigma_{a}=\left(1+\frac{W_{0}}{W_{p}}\right)^{2} \sigma_{v}$

where ;

$\sigma_{a}=\frac{P}{W_{p}^{2}}=$ average pillar stress

$P=$ load total pillar

$W_{0}$ and $W_{p}=$ pillar width and room

$\gamma=$ density of rock

\subsection{Pillar Strength}

Numerous pillar strength formulas have been proposed, but five formulas are used most commonly (Bieniawski, 1984; Peng, 1986). Each formula specifies its own appropriate factor of safety. These are given below:

* Obert - Duvall Approach (1967)

It was derived from laboratory tests on hard rock and elasticity considerations the same relationship. The Formula is given as :

$$
\sigma_{p}=\sigma_{1}\left(0.778+0.222 \frac{w}{h}\right)
$$

According to Obert and Duvall, this equation is valid for w/h ratios of 0.25 to 4.0 , assuming gravity-loading conditions. Through back calculations from mining case histories and utilization of laboratory rock properties, safety factors of 2 to 4 were derived for short and long-term pillar stability, respectively.

* Bienawski Approach

This approach is based on large-scale in situ tests on coal pillars. The general normalize form of the Bieniawski equation is :

$\sigma_{p}=\sigma_{1}\left(0.64+0.36 \frac{w}{h}\right)$

\section{DESIGN \& MODELLING}

\subsection{Room Dimensions and Sizes}

According to the results of the field observational numerical simulation, the generated tension on the pillar rises as the goaf progresses farther up the pillar. In accordance with the development of the goaf edge, it has been determined that the load on the model is rising constantly and will reach a maximum value of $7.87 \mathrm{MPa}$, as indicated in Table 1 . When the goaf edge is in close proximity to the model. Row spacing is used to determine the width of the model that is being considered. The greatest amount of stress that may be induced has been determined using the empirical equation shown below:

$S u=0.025 H+\left(\frac{8.646}{10000}\right) H \sqrt{I} M P a$

Where ;

$S u=$ ultimate induced stress 
$I=$ capability index

$H=$ average cover depth coal seam

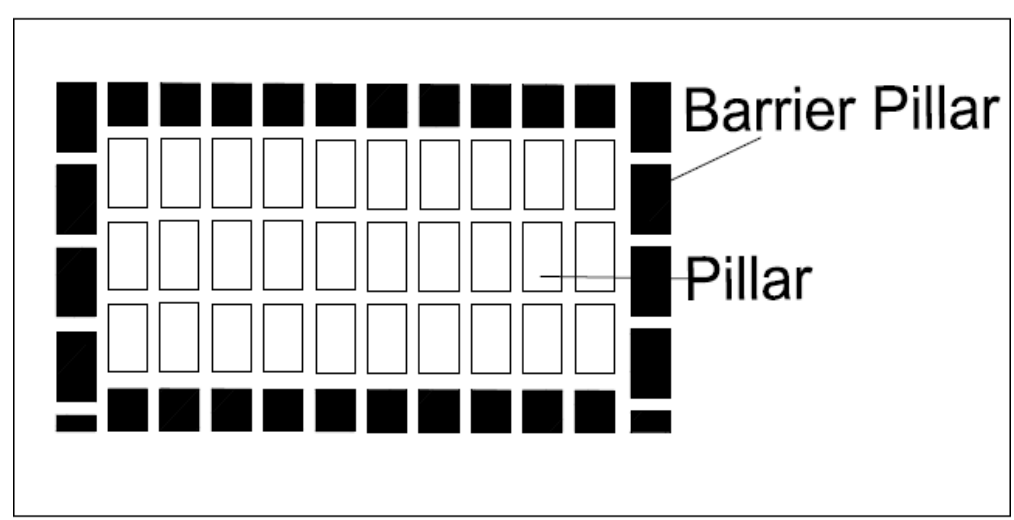

Fig. 1. Development Panel 7 Seam D Coal Mining

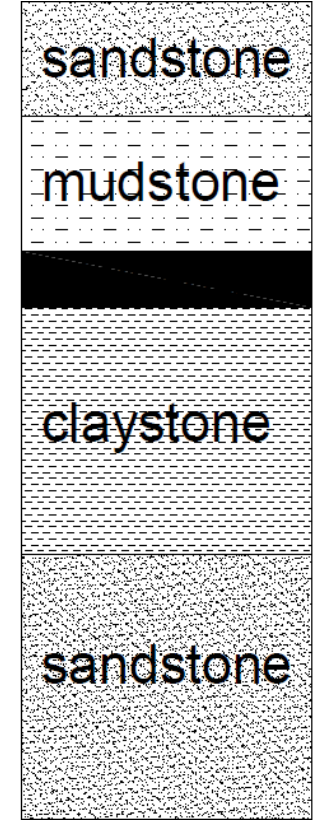

Fig. 2. Lithology in Panel 7

Now, the processes involved in simulating the effect of random variation real room sizes on the stability of the near and major roofs are minor and are not taken into account in the calculation of roof stability. The results of the investigations revealed that the safety factor of the estimated room size is sufficient. The long-term stability study of the rooms was used for the stability analysis.

Using a standard formula, the values of the dependency of immediate roof critical width (IRCW) on geological conditions and on pillar arrangement in block mining were calculated, according to the instruction for mining excavations. 

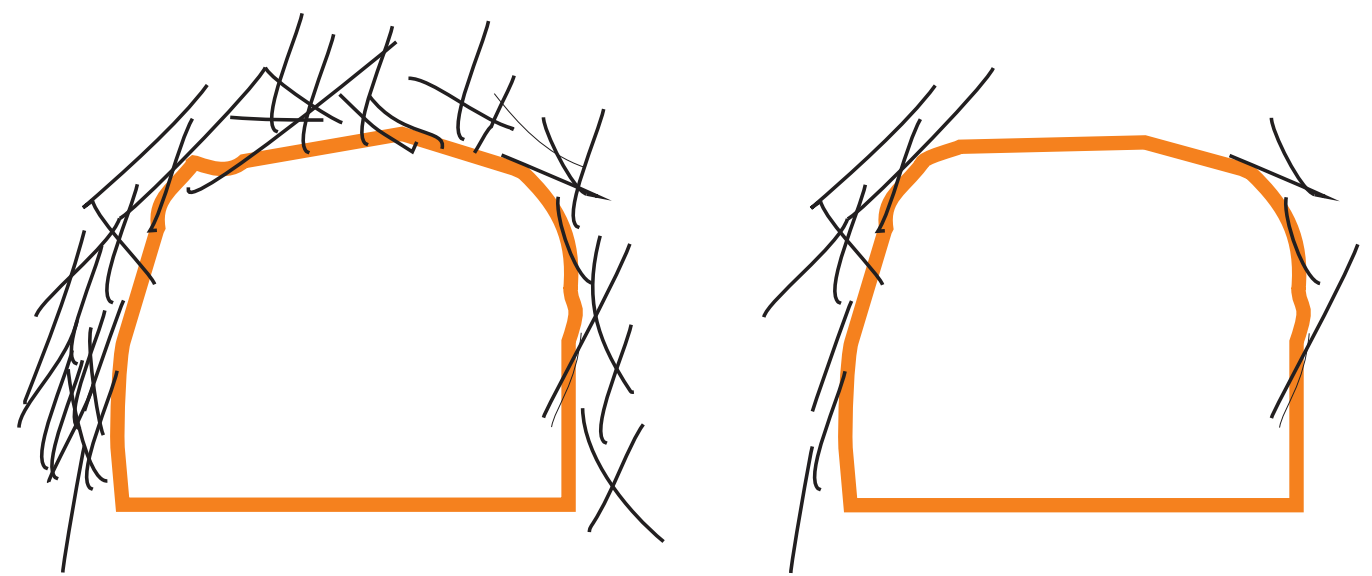

Fig. 3. Rock mass condition instability in pillar excavation

Table 1. Physico Properties of Materials rock strata Seam D and Seam E

\begin{tabular}{|l|c|c|c|c|c|c|c|}
\hline \multirow{2}{*}{ Lithology } & $\begin{array}{c}\text { Water } \\
\text { Content }\end{array}$ & \multirow{2}{*}{ SG } & $\begin{array}{c}\text { Unit } \\
\text { Weight } \\
\text { Natural } \\
\text { slate }\end{array}$ & $\begin{array}{c}\text { Dry } \\
\text { Unit } \\
\text { Weight }\end{array}$ & $\begin{array}{c}\text { Degree of } \\
\text { Saturation }\end{array}$ & $\begin{array}{c}\text { Natural } \\
\text { Porosity }\end{array}$ & $\begin{array}{c}\text { Natural } \\
\text { Void } \\
\text { Ratio }\end{array}$ \\
\cline { 2 - 7 } & $\mathbf{( \% )}$ & & $\left(\mathbf{g r} / \mathbf{c m}^{\mathbf{3}}\right)$ & $\left(\mathbf{g r} / \mathbf{c m}^{\mathbf{3}}\right)$ & $\mathbf{\%}$ & $\mathbf{\%}$ & \\
\hline Soil & 10,65 & 2,64 & 1,79 & 2,21 & 43,76 & 27,84 & 0,38 \\
\hline Claystone 1 & 10,1 & 2,4 & 2,22 & 1,93 & 89,94 & 27,27 & 0,38 \\
\hline Claystone 2 & 5,37 & 2,63 & 2,26 & 2,15 & 62,77 & 18,38 & 0,23 \\
\hline Siltstone 1 & 9,78 & 2,65 & 2,22 & 2,03 & 91,62 & 23,2 & 0,3 \\
\hline Siltstone 2 & 6,86 & 2,64 & 2,36 & 2,21 & 91,97 & 16,45 & 0,2 \\
\hline Sandstone 1 & 12,37 & 2,72 & 2,1 & 2,05 & 91,76 & 26,54 & 0,37 \\
\hline Sandstone 2 & 9,4 & 2,64 & 2,26 & 2,06 & 89,07 & 21,78 & 0,28 \\
\hline Sandstone 3 & 11,68 & 2,77 & 2,33 & 2,05 & 95,48 & 24,58 & 0,32 \\
\hline Coal & 4,68 & 2,51 & 2,29 & 2,3 & 78,63 & 13,5 & 0,15 \\
\hline
\end{tabular}

Table 1 provides the physic-mechanical characteristics of rock coal; Tables 3 and 4 indicate the rock, coal, and other parameters that were taken into consideration while developing the numerical model. The characteristics utilized in the model have been calculated using the Sheorey failure criterion, which can be found here.

Bienawski (1969) conducted a series of in-situ experiments on cubical specimens and discovered that the strength of cubical specimens declines with increasing specimen size and remains constant when the specimen size reaches the critical specimen size of about 5 feet for coal. In this case, the strength of the crucial sample may be a good representation of the strength of an in-situ coal pillar.

Table 2. Mechanical Properties of Materials rock strata Seam D and Seam E

\begin{tabular}{|l|c|c|c|c|c|c|c|}
\hline \multirow{3}{*}{ Lithology } & \multicolumn{4}{|c|}{ UCS } & \multicolumn{2}{c|}{ Triaxial } & $\begin{array}{c}\text { Tensile } \\
\text { Strength }\end{array}$ \\
\cline { 2 - 8 } & UCS & $\begin{array}{c}\text { Poisson } \\
\text { s Ratio }\end{array}$ & $\begin{array}{l}\text { Modulus } \\
\text { Elasticity }\end{array}$ & Strain & $\begin{array}{c}\text { Cohessio } \\
\text { n }\end{array}$ & $\begin{array}{c}\text { Int. Fric. } \\
\text { Angle }\end{array}$ & \\
\cline { 2 - 8 } & $\mathbf{M P a}$ & & $\mathbf{M P a}$ & $\%$ & $\mathbf{M P a}$ & $\left({ }^{\circ}\right)$ & $\mathbf{M P a}$ \\
\hline Soil & 0,85 & - & - & - & 12,62 & 6,93 & - \\
\hline Claystone 1 & 1,9 & 0,28 & 302 & 1,48 & 0,37 & 19,25 & 0,34 \\
\hline Claystone 2 & 9,22 & 0,34 & 435,3 & 1,12 & 1,35 & 20,06 & 0,59 \\
\hline
\end{tabular}




\begin{tabular}{|l|c|c|c|c|c|c|c|} 
Siltstone 1 & 3,79 & 0,33 & 283,85 & 2,21 & 0,69 & 37,79 & 0,42 \\
\hline Siltstone 2 & 3,85 & 0,33 & 505,85 & 2,73 & 0,59 & 27,79 & 0,42 \\
\hline Sandstone 1 & 4,81 & 0,31 & 504,47 & 1,53 & 1,18 & 34,47 & 0,71 \\
\hline Sandstone 2 & 6,13 & 0,33 & 799,11 & 1,76 & 2,99 & 29,44 & 0,6 \\
\hline Sandstone 3 & 1,09 & 0,36 & 104,5 & 1,606 & 0,21 & 20,61 & 0,14 \\
\hline Coal & 4,35 & 0,31 & 348,19 & 2,25 & 0,42 & 24,33 & 1,03 \\
\hline
\end{tabular}

\subsection{Pillar Dimensions}

Based on factors such as room size and geological conditions, or the placement of pillars in a mining block of room and the stability of the pillars (Table 2). According to Peng and Chiang (1984), there are three disturbance zones in overburden movement: the caving zone, the cracked zone, and the continuous deformation zone (Peng \& Chiang, 1984). The immediate roof essential width is determined by a variety of factors, including the mine's height, the mining technique used, and the rock's behavior. There are two phases of overburden movement in the immediate roof critical width: the first roof weighting interval and the periodic roof weighting interval. The first roof weighting interval is the most significant. Table 2 shows the results of determining the immediate roof critical width based on the formula.

Table 3. Calculate Immediate Roof Critical Width (IRCW) seam D

\begin{tabular}{|c|c|c|c|}
\hline Parameter & Symbol & Unit & Value \\
\hline Depth of Mine & $\mathrm{h}$ & $\mathrm{m}$ & 400 \\
\hline Height of area & $\mathrm{H}$ & $\mathrm{m}$ & 2 \\
\hline Width of area & Wo & $\mathrm{m}$ & 3,50 \\
\hline Panel width & $\mathrm{P}$ & $\mathrm{m}$ & 150 \\
\hline Density of rock & $\gamma$ & $\mathrm{kg} / \mathrm{m}^{3}$ & 2.200 \\
\hline UCS Coal & $\sigma_{c}$ & $\mathrm{~kg} / \mathrm{m}^{3}$ & $443.567,55$ \\
\hline Vertical insitu stress & $\sigma_{v}$ & $\mathrm{~kg} / \mathrm{m}^{3}$ & 880.000 \\
\hline Bulking Original Factor & $k_{0}$ & & 1,20 \\
\hline Bulking Residual Factor & $k_{r}$ & & 1,07 \\
\hline Curvature coefficient & $\mathrm{c}$ & & 0,45 \\
\hline Sagging & $d$ & $\mathrm{~m}$ & 0,9 \\
\hline Height IRCW Original & $h_{\text {ircw }}$ original & $\mathrm{m}$ & 5,5 \\
\hline Height IRCW Residual & $h_{\text {ircw }}$ residual & $\mathrm{m}$ & 15,7 \\
\hline
\end{tabular}

Table 4. Calculate Immediate Roof Critical Width (IRCW) seam E

\begin{tabular}{|c|c|c|c|}
\hline Parameter & Symbol & Unit & Value \\
\hline Depth of Mine & $\mathrm{h}$ & $\mathrm{m}$ & 485 \\
\hline Height of area & $\mathrm{H}$ & $\mathrm{m}$ & 3,50 \\
\hline Width of area & Wo & $\mathrm{m}$ & 3,50 \\
\hline Panel width & $\mathrm{P}$ & $\mathrm{m}$ & 150 \\
\hline Density of rock & $\gamma$ & $\mathrm{kg} / \mathrm{m}^{3}$ & 2.200 \\
\hline UCS Coal & $\sigma_{c}$ & $\mathrm{~kg} / \mathrm{m}^{3}$ & $443.567,55$ \\
\hline Vertical insitu stress & $\sigma_{v}$ & $\mathrm{~kg} / \mathrm{m}^{3}$ & 1.067 .000 \\
\hline Bulking Original Factor & $k_{0}$ & & 1,20 \\
\hline Bulking Residual Factor & $k_{r}$ & & 1,07 \\
\hline Curvature coefficient & $\mathrm{c}$ & & 0,45 \\
\hline Sagging & $d$ & $\mathrm{~m}$ & 1,58 \\
\hline Height IRCW Original & $h_{\text {ircw }}$ original & $\mathrm{m}$ & 9,35 \\
\hline Height IRCW Residual & $h_{\text {ircw }}$ residual & $\mathrm{m}$ & 18,91 \\
\hline
\end{tabular}




\subsection{Modelling in 2 Dimension}

\subsubsection{Boundary and Geometry}

For the discretizational perspective of the model, there were four numbers of layers comprising the following elements: ground floor, coal, shale (immediate roof), and roof. The global model of a portion of the panel has the following dimensions: $26.0 \mathrm{~m}$ in width, $1 \mathrm{~m}$ in length, and $62.8 \mathrm{~m}$ in height. The discretization is more concentrated in the gallery where the bolt has been placed and less concentrated on the pillar since the emphasis is on interpreting the behavior of the rock bolt in the gallery when it is in contact with rock mass and grout. In the pillar, the grid patterns in the $\mathrm{x}, \mathrm{y}$, and $\mathrm{z}$ directions are 5,10, and 10, while in the gallery, the grid patterns are 50,10, and 50 .

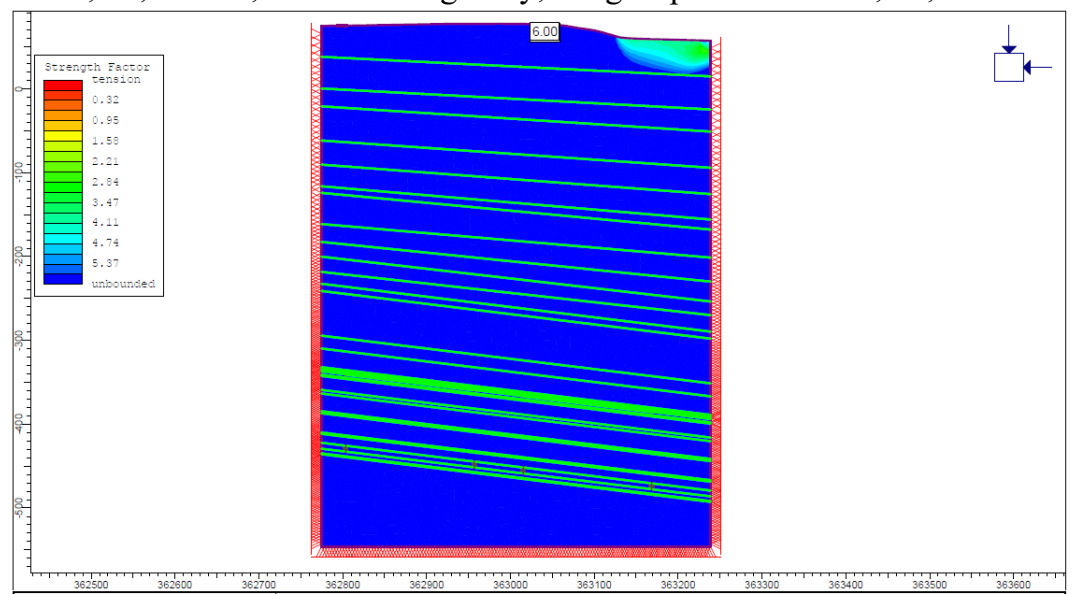

Fig. 4. Plan view of 2 Dimensional modelling

Because the depth of cover of the coal seam is about $400 \mathrm{~m}$ and the height of our model is around $100 \mathrm{~m}$ above the coal seam, This results in the application of $8.5 \mathrm{MPa}$ vertical stress to the top of the model, which was calculated using the formula in equation 2 with gravity loading, while $7.03 \mathrm{MPa}$ horizontal stress was calculated using the formula in equation 3 with gravity loading, with the axes of the formula in equation 3 being parallel to each other and perpendicular to each other. Previously given boundary conditions to the sides, top, and bottom of the global model have become fixed.

The rock strata for the immediate roof critical width were simulated using an elastic model, which was developed by the researchers. During the modeling process, it was taken into account as a strain softening material. Vertical tension in situ may be expressed as follows::

$\sigma_{v}=\rho \cdot g \cdot h$

And, using sheorey formula the value is :

$k=0.25+7 E_{h}\left(0.001+\frac{1}{z}\right)$

Where :

$\mathrm{E}_{\mathrm{h}}=$ Modulus young of Rock strata

$z=$ depth of excavation 


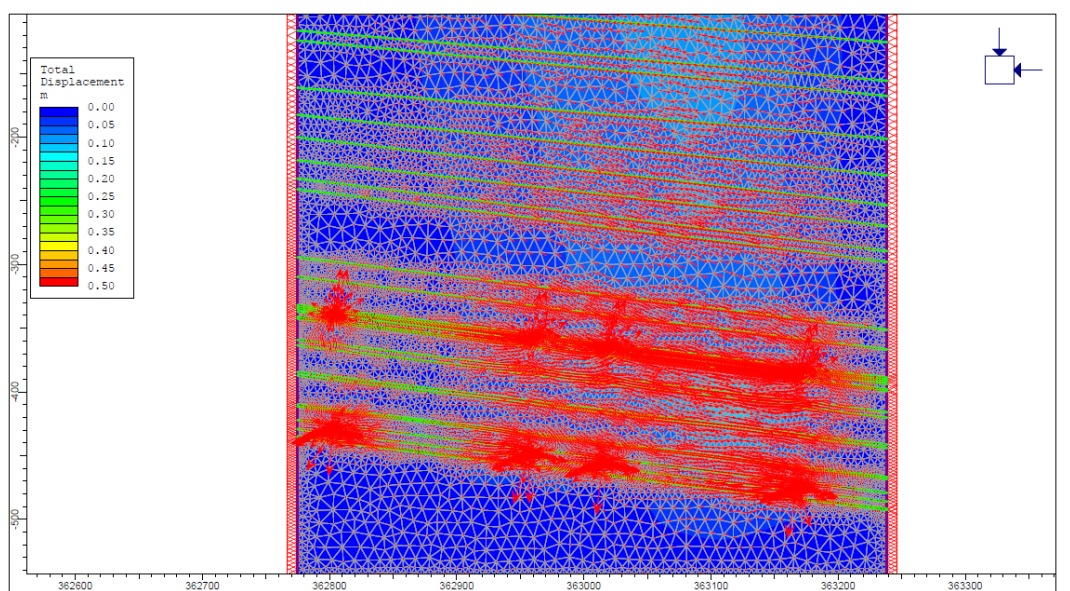

Fig. 5. Stress path in deform pillar

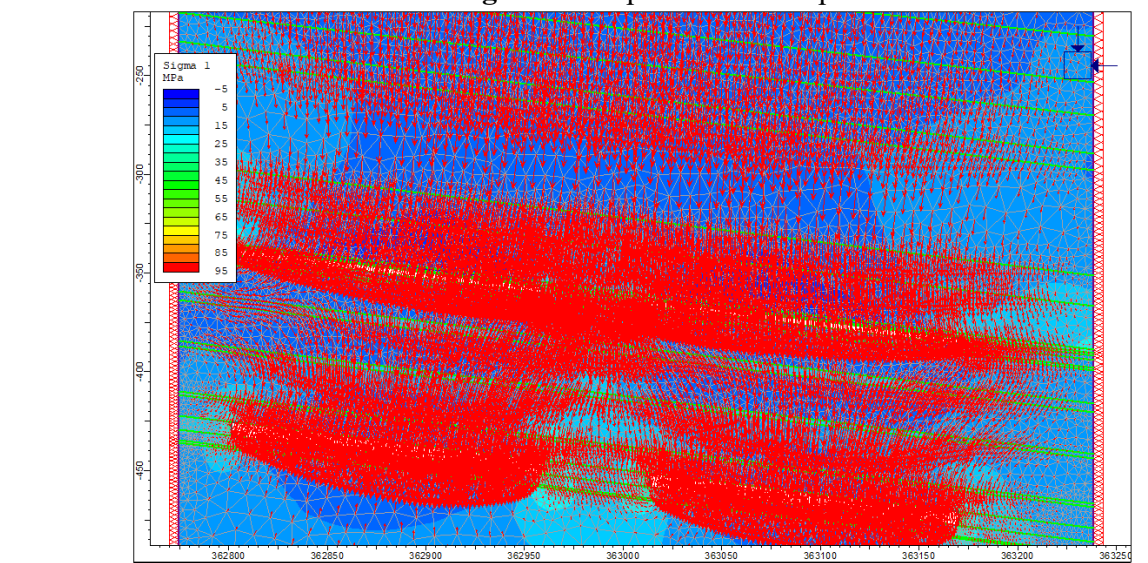

Fig. 6. Vertical stress near goaf and pillar

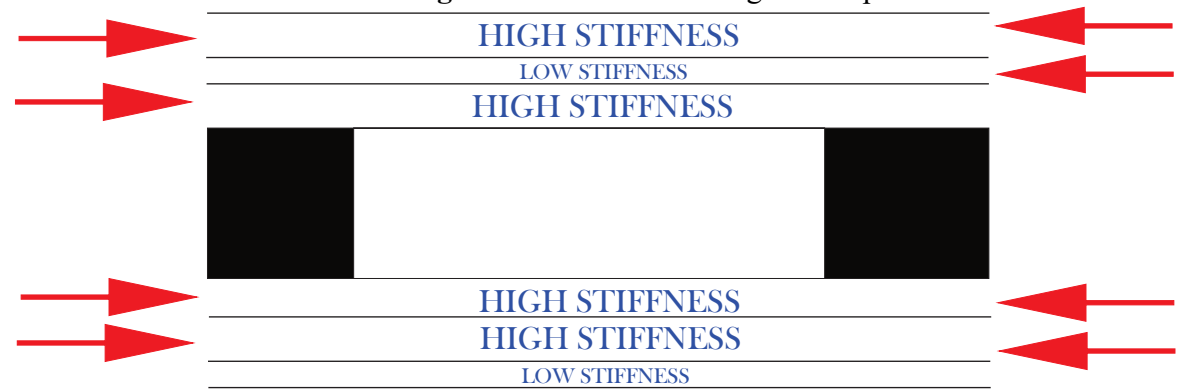

Fig. 7. Variation stress of different layer in rock strata

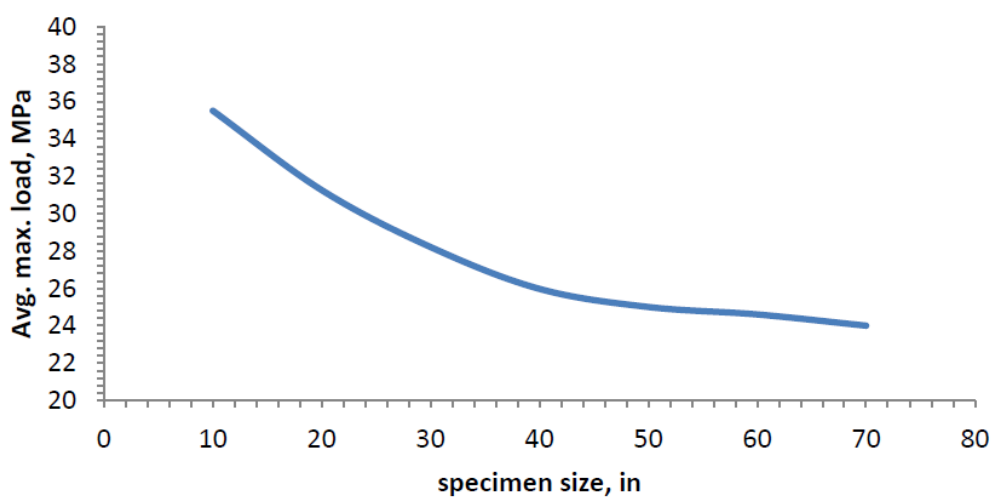


Fig. 8. Compressive Strength with variation coal sample size

\section{Conclusion}

According to the findings of the $2 \mathrm{D}$ numerical model, the greatest stress on the pillar occurs during the development stage and is 7.28 MPa. It has been found that when the goaf edge is advanced, the value of induced stress and axial load on the excavation increases. This was seen during the pillar stage (some views on drill and blasting activity). As a result of the experiment, the highest produced stress was found to be $7.87 \mathrm{MPa}$, and the maximum displacement measured on the goaf and barrier pillar was 0.15 meters $(15 \mathrm{~cm})$. When comparing the maximum shear strain between the model anticipated and field-monitored data, a similar conclusion has been reached as well. For lack of a better expression, the suggested three-dimensional crucial roof model has sufficient precision to accurately mimic its behavior. Additionally, it has been shown that the barriers pillar may substantially enhance the stiffness of the rocks in the surrounding area. Understand why roof bolts may assist to minimize roof drooping in subterranean entrances by providing a structural support for the roof.

\section{References}

[1] Alehossein, Habib and Poulsen, Brett A., 2010, “Stress Analysis of Longwall Top Coal Caving”. Int. Journal of Rock Mechanics and Mining Series. 47, 30 - 41. Barczak (1992).

[2] Bienawski, Z.T. 1984. "Rock Mechanics Design in Mining and Tunnelling". A.A. Balkema, Boston

[3] Bienawski, Z.T. 1984. "The Effect of Specimen Size on The Strength of Coal”. Int. Journal Rock Mechanics and Mining Series.

[4] Galvin, J.M.2016."Ground Engineering-Principles and Practices for Underground Coal Mining". Springer Cham Heidelberg. New York.

[5] Holland, C. T.1964.”The Strength of Coal in Mine Pillars". Paper in Proceedings of the 6th U.S. Symposium on Rock Mechanics. Univ, MO. Rolla:450-466.

[6] Mark,C., and Bieniawski, Z. T.1986."An Empirical Method for the Design of Chain Pillars in Longwall Mining". Paper in Proceedings of the $27^{\text {th }}$ U.S.Symposium on Rock Mechanics. New York : 415-422.

[7] Obert, L. and W. I. Duvall, "Rock Mechanics and the Design of Structures in Rock, Wiley, New York (1967).

[8] Peng, Syd S. 1986. "Coal Mine Ground Control”. John Wiley \& Sons, Inc. Canada.

[9] Peng, Syd S and Chiang, H. S.1984.”Longwall Mining”.John Wiley \& Sons, Inc. Canada. 